\begin{tabular}{|c|c|c|}
\hline $\begin{array}{l}\text { PKS } \\
\text { PUBLC } \\
\text { KNOWLDGE } \\
\text { PROJECT }\end{array}$ & $\begin{array}{c}\text { REVISTA DE GEOGRAFIA } \\
\text { (RECIFE) } \\
\text { http://www.revista.ufpe.br/revistageografia }\end{array}$ & 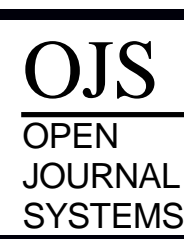 \\
\hline
\end{tabular}

\title{
DA TERRA SECA À TERRA MOLHADA: REVISITANDO EUCLIDES DA CUNHA
}

\author{
Antenor da Silva Ferreira ${ }^{1}$, Odenei de Souza Ribeiro ${ }^{2}$, Aldenor da Silva Ferreira ${ }^{3}$ \\ ${ }^{1}$ Mestre em Sociologia pela Universidade Federal do Amazonas.Email: antenorferreira2015@ gmail.com \\ ${ }^{2}$ Professor da Universidade Federal do Amazonas. Email: ribeiroode@ @otmail.com \\ ${ }^{3}$ Professor da Universidade Federal do Mato Grosso do Sul, Campus de Naviraí. Email: \\ aldenorferreira@yahoo.com.br
}

Artigo recebido em 02/02/2017 e aceito em 17/08/2017

\begin{abstract}
RESUMO
Este trabalho constitui-se num exercício exegético das obras "Os Sertões" e "À Margem da História", de Euclides da Cunha. Realiza-se uma comparação entre as duas obras sobre os temas Integração regional, Paisagem e Topofilia. Os objetivos são: identificar como o autor entende e propõe a integração das regiões Nordeste e Norte à nação brasileira e, ainda, compreender como o autor classifica a paisagem e os espaços do Nordeste e da Amazônia. A metodologia consta de pesquisa bibliográfica, um exame das duas obras, sem negligenciar os demais escritos do autor, bem como fontes secundárias. A temática da integração regional é a grande contribuição de Euclides da Cunha, pioneiro nesse tema, em relação à integração da Amazônia. $\mathrm{O}$ autor descreve a paisagem para valorizar a luta do sertanejo contra a natureza, evidenciando-lhe a bravura, traço psicológico proposto por ele como o cerne da nacionalidade e modelo para a nação.
\end{abstract}

Palavras-chave: Integração; Paisagem; Topofília; Experiência.

\section{FROM DRY LAND TO WET LAND: REVISITING EUCLIDES DA CUNHA}

\begin{abstract}
This work constitutes an exegetical exercise about 'Os Sertões' and 'À Margem da História' written by Euclides da Cunha. A comparison of the two books is made, considering the Regional Integration issues, as well as Landscape and Topophilia. The goals of this article are to identify how the author understands and proposes the integration of Northeast and North of the Brazilian nation, and yet understand how the author classifies the landscape and the spaces of the Northeast and Amazon. The methodology consists on bibliographic research, an examination of the two books, without neglecting the other writings of the author, as well as secondary sources. The subject of regional integration is the greatest contribution of Euclides da Cunha, a pioneer in this theme, when it comes to the Amazon integration. The author describes the landscape to highlight the struggle of the backcountry and the nature, showing his bravery - psychological trait proposed by the author as the core of the nationality and role model for the nation.
\end{abstract}

Key-words: Integration; Landscape; Topophilia; Experience.

\section{INTRODUÇÃO}

Euclides da Cunha é um autor clássico do pensamento social brasileiro, comprometido com as transformações sociais e empenhado na construção de um projeto de identidade nacional, o que aparece nos textos "Os Sertões" e "À Margem da História" como preocupação 
recorrente. Independentemente da validade ou não das propostas de Euclides da Cunha nessa questão, parece importante entender que tipo de integração regional é proposta nesses textos, uma vez que, tanto o sertanejo nordestino, quanto o caboclo amazônico aparecem alijados das preocupações governamentais da federação. Euclides da Cunha aparece como autor engajado e incontornável nessa temática, pela maneira como propôs a intervenção estatal na construção da infraestrutura necessária para o desenvolvimento das regiões.

Percorridas quase duas décadas do século 21, os problemas conhecidos em séculos anteriores ainda se multiplicam e se complexificam com o passar dos anos - a exemplo da exploração desequilibrada de madeira, da mineração clandestina, do crescimento desordenado das cidades, dos conflitos fundiários, da questão indígena, do atraso educacional, dentre outros. Conforme a definição de Schneider et al. (2000), a Amazônia vive um boom-colapso: um período de grande prosperidade econômica - boom - seguido de forte declínio e estagnação - colapso. Essas questões atestam a relevância de Euclides da Cunha. Estudá-lo é revisitar um autor que conheceu o povo brasileiro e sua realidade não por ouvir falar ou por sondar à distância, mas por experimentar seus dramas, que pode auxiliar na escolha de novos rumos diante de uma temática que continua em aberto. Nesse sentido, este trabalho objetiva compreender como Euclides da Cunha entende e propõe a integração das regiões Norte e Nordeste à nação brasileira, analisando comparativamente as obras "Os Sertões" e "À Margem da História”, por meio de um exame direto dos textos.

Percebe-se dos escritos de Euclides um descontentamento para com a paisagem amazônica. O que o teria levado a se expressar com tamanho desgosto, quando o seu objetivo era integrá-la à nação? Para entender essa questão buscou-se localizar o autor no seu tempo, combinando trajetória de vida e consciência social, de modo a alcançá-lo no ambiente em que os livros foram escritos. Nota-se que os sentimentos do autor em relação à paisagem expressados no livro "Os Sertões" são inversos aos expressados no livro "À Margem da História”. No primeiro vê-se admiração. No segundo, descontentamento. Assim, foi delienada a hipótese de que há uma relação entre a regularidade monocromática e topográfica da paisagem amazônica com o descontentamento de Euclides da Cunha em relação a ela. Tal como a monocromia da caatinga e a estrutura rasteira daquele tipo de vegetação lhe causou descontentamento, assim também, a paisagem amazônica com a sua característica de regularidade cromática e de pouca visibilidade do horizonte. Propõe-se explicar esse descontetamento a partir do conceito de Topofilia e com isso busca-se justificar o autor da acusação de preconceito para com a região. A hipótese aqui formulada é que a ambientação 
de infância do autor em região montanhosa foi o elemento vinculante que produziu o descontentamento em relação à paisagem amazônica.

Assim, o tema aqui proposto justifica-se no sentido de que permite que Euclides da Cunha seja percebido sob um novo olhar, capaz de retirar dele a pecha de preconceituoso e permitir que a sua real preocupação sobressaia do seu texto. Descolado dessa pecha é possível flagrar em sua obra, por exemplo, a razão do despovoamento do interior, ou da dependência extremada de suprimentos externos, dos quais $70 \%^{1}$ são importados de outros estados brasileiros e de outros países.

As estratégias de investigação utilizadas constaram de uma revisão da literatura do autor, centrada em "Os Sertões" e “À Margem da História”, sem negligenciar os demais escritos. Quanto do uso de fontes secundárias, procurou-se localizar textos pertinentes e avaliar a sua credibilidade, bem como a sua representatividade no que tange à obra de Euclides da Cunha. Realizou-se um exame dos comentadores para compreender sua contribuição e auxiliar na consolidação da proposta deste trabalho. Foram lidas as obras correlacionadas com o autor, como artigos acadêmicos, livros de autores locais e nacionais e biografias.

\section{Da terra seca à terra molhada: o Nordeste e a Amazônia de Euclides da Cunha}

\section{A integração do Nordeste - uma necessidade cultural}

Está estabelecido na literatura científica a respeito dos escritos de Euclides da Cunha os propósitos da sua produção literária. Euclides é um homem de ação, ou de missão, que se vê na obrigação de interferir na realidade para mudá-la. O campo da política é o seu preferido, em que o tema central é a Integração Regional. Está implícita nessa preocupação a crítica ao federalismo brasileiro por deixar no ostracismo os estados do Nordeste e do Norte. Na mente euclidiana, bem como na de seus contemporâneos, o Brasil era um país ainda por ser feito. Euclides identifica o problema da nacionalidade pelo viés da regionalidade, ou melhor, da integração regional no processo de formação e consolidação não apenas do que viria a ser o povo brasileiro, mas também de seus próprios limites geográficos.

Euclides denuncia a indiferença do Brasil litorâneo em relação ao Nordeste e à Amazônia. Quanto ao Nordeste o Sul deve considerar à luta pela sobrevivência do homem

\footnotetext{
${ }^{1}$ Entrevista com o diretor do Sindicato dos Feirantes do Estado do Amazonas, Deuticilan Barreto, concedida ao site new.d24am.com, publicada no dia 26 de fevereiro de 2015.
} 
sertanejo e auxiliá-lo com obras de engenharia que o fixem na terra, levando em conta o fato de que o sertanejo é um forte que já demonstrou ser capaz de suplantar suas agruras. O reverdejar do sertão na breve temporada de chuvas é uma prova de que a terra tem potencial para sustentar a sua gente, faltando-lhe o emprego de tecnologia que domine os extremos e suavize a luta do homem contra a natureza hostil. Nota-se, no entanto, que Euclides romantiza o horror da seca quando diz que o sertanejo a vê chegando e não se apavora. Contrariamente a outros povos igualmente afligidos por intempéries, o "sertanejo adivinha-se e prefixa-a graças ao ritmo singular com que se desencadeia o flagelo (...). A seca não o apavora. É um complemento à sua vida tormentosa, emoldurando-a em cenários tremendos. Enfrenta-a estoico"2 (Cunha, 1998, p. 136). No entanto, Euclides sustenta que essa determinação no coração do sertanejo de sobrepujar o flagelo, ${ }^{3}$ é um elemento psicológico relevante, o qual irá compor o que ele chama de cerne da raça.

$\mathrm{Na}$ verdade, a integração na mente euclidiana perpassa por uma reconversão do olhar por parte do Governo da República (Bourdieu, 1989). O que há em relação àquela região é uma cegueira conceitual, uma miopia governamental, uma hermenêutica obtusa, visto na incapacidade da República em fazer a leitura correta do episódio de Canudos. Em lugar de destruir o jagunço, a República deveria tê-lo estudado, como uma ruinaria. Canudos deveria ter despertado aquela curiosidade científica que despertaria um sítio arqueológico, no entanto, reclama o autor, “(...) entre nós, de um modo geral, despertou rancores” (Cunha, 1998, p. $351)$.

Euclides percebe que o Nordeste, tal como a Amazônia, permaneceu invisível aos olhos da nação por três séculos e, se porventura houver uma nação no futuro, haverá que se olhar aquelas regiões com melhores lentes, num mais elevado exercício hermenêutico, capaz de perceber as especificidades da região, um verdadeiro novo olhar. Para o autor, o episódio de Canudos deveria iluminar o anacronismo que campeou por ambos os lados da disputa, e uma preparação para essa reconversão do olhar se daria reconhecendo a bravura sertaneja pelo simples perguntar-se: "[e]m que batalhas mundo a fora um único jagunço repele uma brigada?" (Cunha, 1998, p. 444). Contrariamente a República negou-se a avaliar mesmo as

\footnotetext{
${ }^{2}$ A declaração de Euclides só cabe se de fato a tese aqui proposta estiver em destaque, isto é, Euclides da Cunha está elevando a bravura sertaneja para pintá-la como o cerne da nacionalidade. Do contrário, é preciso lembrar que a seca destroi o sertanejo, imobiliza-o, torna-o retirante, um "pau-de-arara".

${ }^{3}$ Euclides da Cunha deixa de perceber que esse apego à terra não é exclusividade do sertanejo nordestino, mas, sim, uma característica do homem ligado à terra, do homem rural.
} 
condições do terreno, da alma aguerrida do homem sertanejo, e subestimou suas astúcias, passando pelo vexame de cair por mais de uma vez aos pés de jagunços mal equipados: [s]oldados possantes que vinham resfolegando de uma luta de quatro horas, caíram, alguns mortos por mulheres frágeis" (Cunha, 1998, p. 447, grifo nosso).

O Brasil não conhece o Brasil. Euclides deixa evidente que as seguidas derrotas do exército em Canudos se deveram principalmente ao desconhecimento do terreno, ao despreparo das tropas, "apegadas a uma cultura de empréstimo", marchando como uma coluna prussiana num terreno onde a guerrilha sertaneja era a mais adequada, reforçado pela arrogância com que o Brasil litorâneo sempre olhou para o sertão. Quando foram vencidos, os soldados sofreram mais sob o terreno do que sob as balas inimigas. Quando venceram, não havia do que se orgulhar. Canudos é uma mentira. Eis a vingança de Euclides, para quem vingar é expor o que está oculto em uma penumbra midiática, é dar a conhecer uma realidade de miséria até então desconsiderada. Ao final do conflito, o jagunço revelou-se mais nobre, mais forte, mais tenaz, realizou proezas morais não encontradas nos oficiais do exército e os soldados se revelaram o verdadeiro homem mau, agindo barbaramente em vingança ao orgulho ferido. Euclides parece esclarecer que todas as expedições resultaram do mesmo erro de avaliação da primeira expedição. Está claro para ele que a República continuaria enviando o seu exército para Canudos até que o último homem tombasse, pois não se tratava mais de unificação da Nação como os jornais publicavam, mas de vingança bárbara. $\mathrm{O}$ único fim esperado era o extermínio do arraial.

Sobre o que lutava o exército republicano em Canudos? A imprensa apregoava que se lutava pela unificação do país. A leitura euclidiana, inicialmente litorânea e, portanto, equivocada por ser apoiadora da ação repressora da República, toma agora ares de denúncia. A República reage com brutalidade a um ato de fé sertaneja. Uma fé mistificada, extravagante, sincrética, anacrônica, mas ainda a expressão da alma de um povo que se forjou na miséria. A obra "Os Sertões" termina com esta nota triste, em que se denota a desproporção da força e o equívoco da leitura feita:

Canudos não se rendeu. Exemplo único em toda a História, resistiu até o esgotamento completo. Expugnado palmo a palmo, na precisão integral do termo, caiu no dia 5, ao entardecer, quando caíram os seus últimos defensores, que todos morreram. Eram quatro apenas: um velho, dois homens feitos e uma criança, na frente dos quais rugiam raivosamente cinco mil soldados (Cunha, 1998, p. 585, grifo nosso). 
Essa, definitivamente, não é a forma de unificação da nação que Euclides endossaria. Aqueles mestiços, homens simples que defendiam o seu lar, surgem como "o cerne de uma nacionalidade" (Cunha, 1998, p. 572). Em que sentido? Euclides começa a ver aqui o elemento psíquico procurado para se constituir em elo da nacionalidade e acha-o na bravura sertaneja, não necessariamente restrito ao conceito de raça, mas como resultado de um conjunto de fatores históricos, geográficos e morais. O sertanejo que vence o meio hostil no Nordeste é o mesmo que vence na Amazônia, transparecendo assim que o elo buscado por Euclides se esconde numa disposição de alma, um querer vencer, uma determinação de constituir-se em nação autônoma, cujo exemplo histórico está patenteado na saga sertaneja que se inicia nas terras secas do Nordeste e prossegue pelas terras molhadas da Amazônia.

Percebe-se que o autor, embora identifique como ruim aquele anacronismo cultural sertanejo no Nordeste, reconhece que o homem sertanejo, na sua luta pela vida no sertão, findou por constituir-se em algo distinto, próprio da interação homem-natureza. Há uma herança espiritual do elemento português, bem como há uma cultura própria, que é bárbara, mas que também é original. É esse elemento que está em confronto com a cultura de empréstimo do Brasil litorâneo que Euclides vê como o cerne da nacionalidade. No entanto para que isso se torne aplicável faz-se necessário vencer a miopia do Governo com respeito àquela região, vencendo o abismo histórico que se abriu entre essas duas faces do Brasil, o litorâneo sempre indiferente para com Brasil sertanejo, indiferença que prossegue nos dias atuais. Nunca houve de fato uma nação. O que prevalece é uma colonização do Sul sobre o Norte, numa espécie de imperialismo impróprio, onde as levas de homens do Sul ainda desembarcam no Norte apenas para o saque, como hordas de piratas. O sentimento que anima os homens que se introduzem nos sertões, focados na pilhagem e na extração predatória e descompromissada, sem jamais haver aquele ânimo de tornar aquela terra o seu próprio lar ${ }^{4}$ produz essa miopia. Não é à toa que, embora pratique a extração das seivas amazônicas, o sertanejo transplantado para a Amazônia não seja um invasor aos olhos de Euclides, pois este veio para fixar-se e ser parte da paisagem. Ambas as regiões sofrem da mesma desafeição à terra, da ação de predadores e inimigos da integração sonhada por Euclides.

Encontrada em “Os Sertões”, as palavras seguintes são repetidas quase que ipsis literis acerca da Amazônia em “À Margem da História”, como mostrado em:

\footnotetext{
${ }^{4}$ Euclides parece ignorar, nesse caso específico, as tentativas holandesas de colonização do Nordeste, cujo ânimo era uma colonização de fixação do homem à terra e não meramente de saque, conforme se pode verificar dos registros da Igreja Protestante Holandesa que se implantou no Brasil (Ferreira, 2016).
} 
De sorte que sem precisarem despertar pela cultura as energias de um solo em que não se fixam e atravessam na faina desnorteada de faiscadores, conservam na ociosidade turbulenta a índole aventureira dos avós, antigos fazedores de deserto (Cunha, 1998, p. 220, grifo nosso).

E em:

O aventureiro ali vai com a preocupação exclusiva de enriquecer e voltar; voltar quanto antes, fugindo àquela terra melancólica e empantanada que parece não ter solidez para aguentar o próprio peso material de uma sociedade (Cunha, 1999, p. 49, grifo nosso).

A exploração desordenada praticada por séculos fez com que ambas as regiões estacionassem em seu processo civilizatório. Por civilização, Euclides entende a implantação e o desenvolvimento nas mesmas regiões dos aparatos institucionais e tecnológicos do homem moderno, incluindo o Estado. Sem a fixação do homem na Amazônia, sem o aprimoramento tecnológico do Nordeste e sem as vias de acesso físicas e culturais que ligassem ambas as regiões ao Sul, só poderia ocorrer um descompasso histórico e cronológico entre elas. As regiões dos sertões, bem como o homem sertanejo e o tipo de vida e cultura que ali se fazem, são desconhecidas desse Brasil litorâneo.

Não há espaço para incluir, aqui, outros episódios que indicam a indiferença do Governo para com a Região Nordeste e para com o povo nordestino, tão vívidos na escrita euclidiana, mas será considerado que a obra "Os Sertões" é extremamente lida e conhecida, não havendo necessidade de extensas explicações ou mais exemplos sobre o tema. Pode-se, então, concluir esta parte dizendo que na mente euclidiana a integração do Norte e do Nordeste na vida nacional não é uma digressão, mas uma necessidade premente. Ressalte-se, ainda, que Euclides não atribui ao Brasil litorâneo o modelo para o sertão, mas que seu ponto é que o Nordeste e o Norte estão em descompasso histórico com o homem moderno. Embora criticando o modo de vida mimético do Brasil litorâneo, Euclides reconhece que é ali que está a se realizar o tipo de desenvolvimento desejado por ele para o Nordeste e para a Amazônia.

\section{Paisagem e topofiliação: a janela por onde Euclides olha o mundo}

Fundamentos conceituais

A fazenda Saudade, localizada em Arraial de Santa Rita do Rio Negro, atual distrito de Euclidelândia, Cantagalo, há 390 km da capital, Rio de Janeiro, assim como toda a região 
circunvizinha, se constitui de ondulações montanhosas. A altitude é de 391 metros, com relevo fortemente ondulado, alternando morros arredondados com encostas que variam em $30^{\circ}$ e $40^{\circ}$ graus, conhecido como "mares de morro" (Prefeitura Municipal de Cantagalo, 2016). Nesse cenário, Euclides da Cunha forjou a sua orientação espacial. A sua referência inicial de mundo tem o formato ondulado das montanhas.

As páginas que seguem é uma análise das mesmas obras, ressaltando-se, agora, o lugar da paisagem nesses escritos. Busca-se primeiramente localizar cronologicamente o tema paisagem nas narrativas, de modo a explicar a existência de conhecimentos geofísicos numa obra literária. Em seguida trata-se do contraste emocional do autor quanto ao tipo de paisagem presente e descrita nas obras, com uma explicação das razões que o levaram ao estranhamento do autor em relação à paisagem amazônica.

Assume-se que as longas descrições geofísicas presentes nas obras se devem a um momento histórico específico no desenvolvimento das ciências. Decorre como consequência do período em que literatura e ciência não haviam delimitado suas fronteiras. Trata-se de um habitus científico (Bourdieu, 1989), de uma época. Por outro lado, afirma-se que a experiência e a ambientação de infância de Euclides da Cunha, com toda a carga emocional que delas resulta, influenciou seu olhar quando da sua aproximação da Amazônia, cuja paisagem diverge daquela geografia internalizada e reforçada pelas suas vivências. Assim, afirma-se que a estranheza e desencanto de Euclides resultam de sua ambientação topofílica.

Para a análise da segunda proposição, utiliza-se os conceitos de Experiência e Topofiliação, do geógrafo sino-americano Yi-Fu Tuan, obtidos das obras "Topofilia” (2012) e "Espaço e Lugar: a perspectiva da experiência" (2013), bem como do conceito de Habitus em Pierre Bourdieu (1989), já mencionados e utilizados anteriormente. Trata-se de uma transposição simples e direta do conceito para o objeto, nesse caso, o tratamento dado por Euclides da Cunha ao item paisagem, nas obras já citadas.

Entende-se que não há necessidade de alongar a explanação do conceito bourdieusiano de habitus, considerando-se o alcance que as obras desse autor já obtiveram no meio acadêmico nacional. Basta destacar que Habitus é o sistema de esquemas inconscientes ou profundamente arraigados no interior do indivíduo e que constituem a sua cultura. Esses esquemas se manifestam por meio de disposições duradouras e alcançam todas as experiências passadas, funcionando a cada momento como matriz das percepções do indivíduo, posto que são incorporados desde a infância (Bourdieu, 1989). O habitus é, portanto, produzido e produtor de estruturas mentais e mesmo corporais que resultam em 
representações práticas e normalmente condicionantes, a menos que sejam refletidas por meio de ferramental teórico. O modo como o indivíduo percebe as coisas, como desenvolve suas atividades, sua visão de mundo, procedem desses esquemas arraigados, que o direcionam.

Tuan (2012), tratando da ambientação humana, estabelece uma relação entre o lugar e a percepção que vem pelos sentidos. O corpo humano é sempre o ponto de partida na relação com o ambiente, ou melhor, o homem é a medida de todas as coisas no sentido de que todos os significados surgem a partir dele. No entanto, encontra os seus limites e definições no ambiente em que vive. A relação com o ambiente pode produzir conceitos, vocabulários, definições de tons, sentido de orientação, de espaço, entre outros.

Tuan (2012) define a Percepção como um produto da cultura. E a cultura é em grande medida uma ambientação. "A percepção é uma atividade, um estender-se para o mundo" (Tuan, 2012, p. 30). Nesse sentido, a percepção de um lugar, de um ambiente, resulta da interação qualitativa com o exterior, pois um homem desambientado continua com os seus sentidos, no entanto, "é possível ter olhos e não ver; ouvidos e não ouvir" (Tuan, 2012, p. 30), o que ocorre, por exemplo, com o esquimó que é capaz de perceber os diferentes tons de neve, tal como o nativo da floresta tropical é capaz de perceber os diferentes tons de verde das árvores, o que para o estranho é impossível em princípio, pois ambas paisagens são para ele monocromáticas.

O espaço e o lugar de nascimento, então, são elementos definidores do ser humano porque a partir daí é que se inicia a sua ambientação, a sua percepção e a sua definição de ser no mundo. Tuan (2012) refere-se à ideia de centro, encontrada universalmente, cuja origem é o próprio corpo humano, mas ela abrange também o espaço e o lugar: "em todos os lugares, as pessoas tendem a estruturar o espaço - geográfico e cosmológico - com elas no centro e a partir daí zonas concêntricas (mais ou menos bem definidas) com valores decrescentes" (Tuan, 2012, p. 49). Noções de frente e costas, lado, abaixo e acima, são definições espaciais norteadas pelo corpo de quem fala e de quem ouve: "[o]s elementos verticais na paisagem evocam um sentido de esforço, um desafio de gravidade, enquanto os elementos horizontais lembram aceitação e descanso" (Tuan, 2012, p. 51), isso, em razão de que, usualmente, é a percepção do indivíduo que é posta sobre os objetos, tornando-os significativos e a sua ambientação evoca tais sensações. Quanto mais diferenciada a paisagem a partir de referenciais permanentes, menor a necessidade de adaptação sensitiva. Quanto mais o espaço é indiferenciado, mais extensa a necessidade de definições. Portanto, a ambientação em determinado lugar tem grande importância na visão de mundo de um indivíduo, pois "a visão 
do mundo, se não é derivada de uma cultura estranha, necessariamente é construída dos elementos conspícuos do ambiente social e físico de um povo” (Tuan, 2012, p. 116).

O amor pelo lugar surge a partir das experiências. Esse amor não advém somente do prazer e da satisfação que nele se obtêm, mas também das lutas travadas. As dificuldades trazidas pelas intempéries podem forjar no coração humano o sentimento de orgulho de sobrevivente, tornando o lugar das lutas o locus de sentimentos profundos. A reconstrução de tudo após uma tempestade parece fortalecer o ânimo de permanência. A experiência vivida no lugar, portanto, é o que marca na memória o quadro topofílico.

A paisagem em si tem pouco a contribuir em permanência, pois é mantida viva somente enquanto nela os olhos estão fixos, desfazendo-se tão logo eles se desviem para outros objetos de atenção. No entanto, se a paisagem está associada a um encontro amoroso, uma luta pela vida, uma lembrança de perda, um folguedo, então aquele quadro se fixa na mente como um dado permanente e passa a evocar emoções. $\mathrm{O}$ belo e o feio, o alegre e o triste, são elementos forjados nesse embate da experiência, que ao longo da vida se configuram em categorias permanentes (Tuan, 2012). Como o início da experiência de todo ser humano começa com ele mesmo, desde a descoberta de seus membros até o seu sentido de lugar, aquilo que consolida sua cultura irá servir de parâmetro para a medição das demais experiências, sejam elas de lugar, cosmológicas, afetivas, morais, etc. Grande quantidade de casos foi enumerada por Tuan (2013), em que o amor pelo lugar de origem foi transformado em ponto de referência para ação, deixando claro que o lugar é uma referência construída na mente, a partir dos objetos existentes no mundo, manifestando-se, muitas vezes, em forma de lembranças e, ainda que se esteja distante dele, continua a exercer a sua influência como uma âncora.

Se houvesse espaço neste trabalho, a mesma questão da paisagem poderia ser tratada sob o ângulo de um provável diálogo entre Georg Simmel (1858-1918), e a sua "Filosofia da Paisagem" (2009) e o autor que adotamos, Yi-Fu Tuan. O entendimento é que Simmel (2009) estabelece a paisagem como uma construção mental, um processo espiritual que dá unidade a parcelas de uma infinidade de elementos e objetos exteriores. Uma paisagem se distingue de natureza, sendo a Natureza inteiriça, dotada de uma unicidade permanente, existindo como um todo e, se porventura, um pedaço dela se aparta dessa unidade, deixa imediatamente de ser natureza. Por sua vez, a Paisagem tem a demarcação como essência. Ela é a resultante de um constructo individual que se impõe a uma parcela da realidade exterior, cujos elementos se 
apresentam dispersos e desconexos entre si. Essa unidade criada, denominada de paisagem, é diferente para o sábio, para o religioso, para o agricultor e assim por diante.

Simmel (2009) define a paisagem como um olhar sobre o exterior, profundamente marcado pela individualidade. Nesse sentido, aquilo que Euclides da Cunha vê como "A Terra" em ambas as obras aqui analisadas, seria, antes de tudo, um constructo de sua alma. É nesse ponto que convergem Simmel e Yi-Fu Tuan, pois, para o segundo, a paisagem também é vista a partir do indivíduo. A divergência está em que Tuan atribui à paisagem uma dimensão social. Isso, pois, embora Tuan não chegue à afirmação de que a paisagem é um constructo da mente de quem olha, ele afirma que a paisagem se apresenta como um elemento social unificador, partilhada pelos diferentes olhares comuns dos diversos indivíduos de um povo, que se reproduz em seus signos linguísticos, nas noções de tempo, espaço e dimensão, nos laços afetivos, entre outros. Portanto, a paisagem passa a fazer parte da cosmovisão do indivíduo. Tanto Simmel (2009) quanto Tuan (2013), não se referem à paisagem como algo dado em si mesma. Há uma interação homem-natureza em ambos os autores, mas ocorre uma prevalência do indivíduo sobre a natureza em Simmel, quando separa Paisagem de Natureza e a estabelece como um constructo da mente do indivíduo, enquanto em Yi-Fu Tuan a paisagem é correlata da natureza como meio ambiente, atribuindo a ele a capacidade de influir sobre a mente humana.

Simmel (2009) tem o indivíduo como emancipado da natureza, enquanto Tuan (2013) tem o homem como relacionado com o lugar, sendo esse um constructo da mente, em que a natureza fornece os elementos físicos e sensoriais que permitem ao homem sua localização no mundo. Nesse sentido, a aproximação entre os dois autores está em que a Paisagem de Simmel é semelhante ao Lugar de Tuan.

\section{A Paisagem como elemento norteador}

A paisagem em "Os Sertões"

Observando-se as obras em tela sob as noções de Experiência e Topofilia, percebe-se Euclides da Cunha revelando-se como pessoa dotada de um senso de beleza e de uma filiação marcado por ambientes montanhosos. Esse senso do belo revela-se ligado aos sentimentos que exalam de sua alma, dada a espontaneidade com que aparecem no texto. Observa-se pela estrutura da frase, pelo contexto das obras, pela mudança de humor, que os afetos e desafetos 
revelados para com determinada paisagem não advêm de uma atitude consciente, mas do coração, sendo, portanto, uma verbalização da experiência topofílica.

O estranhamento de Euclides para com a paisagem amazônica e sua planura, sua regularidade física e cromática, resulta do contato com uma paisagem diversa de sua experiência topofílica. Em "Os Sertões" constata-se que a paisagem toma um lugar privilegiado na narrativa. São 70 páginas de um capítulo inteiro dedicado à paisagem natural, denominado "A Terra", no qual a Geografia Física brota vertiginosa, em descrições pormenorizadas dos diferentes tipos de solos e vegetações. É nesse ambiente descritivo que o autor deixa transparecer a sua preferência pelo horizonte amplo, pela vista desimpedida que permita contemplar maiores lonjuras, impregnado pela estimulação nervosa trazida pela irregularidade do terreno que ali se assemelha em muito ao locus de sua Experiência.

Doravante, analisar-se-á recortes do capítulo “A Terra”, no intuito de provar o ponto em questão. Ao expressar admiração diante de um paredão escarpado, Euclides não apenas o descreve em termos científicos ou literários, mas ele descreve-o com paixão, com admiração, com afeição. Esse ânimo revela a sua localização no mundo, sua vinculação a um lugar que nós sabemos ser o seu local de nascimento, um lugar montanhoso, de onde ele contempla, julga e compara os demais lugares, não obstante o seu Positivismo que o obrigaria a uma suposta neutralidade científica. Todo homem julga a partir de sua cosmovisão (Tuan, 2013). Note-se o tom emotivo que o autor expressa sobre os chapadões que se alteiam a partir do Sul: “(...) se encurvam em desmedido anfiteatro, alteando as paisagens admiráveis que tanto encantam e iludem as vistas inexpertas dos forasteiros (...)" (Cunha, 1998, p. 12), e ainda mais à frente, "[a] terra atrai irresistivelmente o homem, arrebatando-o na própria correnteza dos rios (...)" (Cunha, 1998, p. 14). Euclides é repetitivo ao afirmar que essas formações geológicas são "esplêndidas” e, ainda, “[...] paragem formosíssima dos campos gerais, expandida em chapadões ondulantes - grandes tablados onde campeia a sociedade rude dos vaqueiros [...]" (Cunha, 1998, p. 16-7).

Euclides revela seu gosto pelo contraste e pela irregularidade que percebe no quadro físico em seu redor. Suas lembranças afetivas refletem-se na visão do quadro atual que contempla, influenciando-o como uma referência. O quadro que vê é semelhante ao quadro que ele ama. Daí sua afeição ao dizer "e o observador que seguindo este itinerário deixa as paragens em que se revezam, em contraste belíssimo, a amplitude dos gerais e o fastígio das montanhas, ao atingir aquele ponto estaca surpreendido (...)” (Cunha, 1998, p. 18). Essa referência é uma preparação que Euclides faz para aquilo que ele irá descrever logo a seguir, a 
paisagem do sertão baiano. Note que ele irá descrever uma região que não é a sua, no entanto, a expressão aferuosa continua, em razão de que não é a linha demarcatória de regiões políticas que o localizam no mundo, mas a sua experiência topofílica, onde a montanha aparece como o elemento norteador do belo, do contraste em oposição à continuidade monótona. Note-se o afeto quando diz: “[é] uma paragem impressionadora. (...) relevos estupendos” (Cunha, 1998, p. 24). Por mais de uma vez o autor explicita o seu gosto pela irregularidade dos acidentes geográficos, que, aos seus olhos, são "majestosas ruinarias de castelos" (Cunha, 1998, p. 25). E prossegue dizendo com a mesma ternura que:

“(...) por mais inexperto que seja o observador - ao deixar as perspectivas majestosas, que se desdobram ao Sul, trocando-as pelos cenários emocionantes daquela natureza torturada, tem a impressão persistente de calcar o fundo recém-sublevado de um mar extinto (...) (Cunha, 1998, p. 27).

Euclides afeiçoou-se desde a infância ao horizonte amplíssimo que se desdobra diante de alguém que olha do alto para o vale. Sua simpatia para com o cenário escarpado do sertão é clara: “(...) os gerais pelo teso das cordilheiras, dando aos quadros naturais a encantadora grandeza de perspectivas em que o céu e a terra se fundem em difusão longínqua e surpreendedora de cores [...]" (Cunha, 1998, p. 33-4). Note-se a emoção quando a referência é à favela. Ali Euclides supõe adentrar a alma do sertanejo, então ele diz que, observando dali, o matuto até mesmo acredita ser ali o céu. Afirma-se que não apenas o matuto, mas o próprio Euclides se identifica com o lugar, já que o descreve com terna afeição, exprimindo aquela experiência que somente os habitantes de regiões montanhosas ou de campinas gerais podem experimentar, que é a alentadora sensação de se enxergar o infinito: “[e]m roda, uma elipse majestosa de montanhas" (Cunha, 1998, p. 35).

Veja-se agora o contraste. Quando a regularidade na paisagem é evidente seja por monocromia, seja por ausência de ondulações, Euclides a descreve negativamente, manifestando desgosto. Comparando a caatinga com as estepes, ele prefere a última, pela mesma razão de preferir as montanhas: a possibilidade de ver ao longe, desimpedido de obstáculos: “[e]ntão, a travessia das veredas sertanejas é mais exaustiva que a de uma estepe nua. Nesta, ao menos, o viajante tem o desafogo de um horizonte largo (...)" (Cunha, 1998, p. 46). Já quanto à caatinga ele diz: "a caatinga o afoga; abrevia-lhe o olhar (...) imutável no aspecto desolado (...)" (Cunha, 1998, p. 46).

Nada que seja regular, que o impeça de ver ao longe, que se apresente num único plano, é belo para Euclides, seja o verde amazônico, seja a caatinga cinzenta. O belo está na 
irregularidade das montanhas e no horizonte infindo. Ainda que o sentimento topofílico não seja determinista, é inegável que há nesses recortes da escrita euclidiana uma expressão de topofilia norteando-lhe os pensamentos. Sim, a janela por onde Euclides olha o mundo tem o formato das ondulações montanhosas.

\section{A paisagem em "À Margem da História"}

Pelo exposto acima já se pode antecipar que Euclides da Cunha não amou a paisagem amazônica. Nem poderia amá-la, pois tudo ao redor está em desacordo com sua topofiliação. Não é preconceito ou desdém. Sob o título de "Impressões Gerais", Euclides começa o livro “À Margem da História" de maneira melancólica e absurdamente franca. A paisagem não lhe agrada. Mais ainda, ela o decepciona, de modo que ele se sente oprimido, quase claustrofóbico. Então ele diz: “[a]o revés da admiração ou do entusiasmo, o que nos sebressalteia geralmente, diante do Amazonas, no desembocar do Dédalo florido do Tajapuru, aberto em cheio para o grande rio, é antes um desapontamento (...)” (Cunha, 1999, p. 1). O seu lugar de origem é o seu ponto de referência, pois diz que toda a Amazônia não se equivale ao "(...) seguimento do litoral que vai de Cabo Frio à Ponta do Munduba" (Cunha, 1999, p.

1). Euclides reconhece a grandeza do quadro que vê, mas nega-lhe a beleza, ao dizer que "é, sem dúvida, o maior quadro da Terra; porém chatamente rebatido num plano horizontal (...)" (Cunha, 1999, p. 1). E mais uma vez, o elemento ausente nesse quadro são as montanhas, como quando o autor lamenta que "(...) mal alevantam de uma banda, à feição de restos de uma enorme moldura que se quebrou, as serranias de arenito de Monte Alegre e as serras graníticas das Guianas" (Cunha, 1999, p. 2).

O espírito de Euclides altamente estimulado pela irregularidade topográfica do Sul o faz estranhar um lugar em que a monotonia e a regularidade física da paisagem são uma constante. Veja-se mais uma vez: “(...) como lhe falta a linha vertical, preexcelente na movimentação da paisagem, em poucas horas o observador cede às fadigas de monotonia" (Cunha, 1999, p. 2). O autor reclama não apenas da regularidade topográfica, mas sua estranheza se estende ao quadro como um todo. $\mathrm{O}$ verde permanente e abundante da floresta que se alteia desde a barranca do rio retira-lhe o elemento essencial do belo, que é a visão ampliada: “(...) quem segue pela mata vai com a vista embotada no verde-negro das folhas (...)" (Cunha, 1999, p. 02). Por seu turno, o rio não ajuda. Ele é uma repetição de si mesmo. Para Euclides: 
[n]o Amazonas, em geral, sucede isto: o observador errante, que lhe percorre a bacia em busca de variados aspectos, sente, ao cabo de centenares de milhas, a impressão de circular num itinerário fechado, onde se lhe deparam as mesmas praias ou barreiras ou ilhas, e as mesmas florestas e igapós estirando-se a perder de vista pelos horizontes vazios (Cunha, 1999, p. 12, grifos nosso).

Por fim, a prova final de que a razão da estranheza de Euclides não está na paisagem em si, mas nele mesmo. Quando se refere à experiência vivida pelo visitante que chega à Amazônia no capítulo 3 - "Um Clima Caluniado" -, Euclides assim se reporta: "[e]ntra no Amazonas. Reanima-se um momento ante a fisionomia singular da terra; mas para logo acabrunha-o a imensidade deprimida - onde o olhar lhe morre no próprio quadro que contempla" (Cunha, 1999, p. 29). E prossegue expressando a falta que lhe faz não "apenas a saudade da terra nativa, mas da Terra, das formas naturais tradicionalmente vinculadas às nossas contemplações, que ali se não veem (...)”(Cunha, 1999, p. 29).

Saudade da terra nativa. Contemplações que ali não se veem. O que se tem é uma confissão textual de que Euclides da Cunha está olhando o quadro amazônico sob a lente de sua experiência topofílica, forjada na região montanhosa da Serra do Mar. Ele não pode ver como belo nada além do que é belo no interior de sua alma. Haverá quem indague se o sentimento topofílico pode ser tão avassalador, como uma disposição duradoura, e generalizante, como se tem afirmado aqui, e a resposta é que, no caso em tela, sim. Euclides da Cunha expressa literalmente que suas contemplações estão presas a um tipo de horizonte que ele não vê na Amazônia e essa é a razão de seu descontentamento.

\section{A Paisagem como literatura em missão}

No texto "Os sertões"

Propõe-se, aqui, mostrar que há uma intencionalidade no recurso utilizado pelo autor. Ao descrever a paisagem Euclides visa indicar as condições das relações humanas com o seu meio físico para ressaltar a bravura do homem. Vê-se no capítulo "A Terra", a intencionalidade de Euclides refletida na ênfase dada à hostilidade do relevo, da vegetação, do clima do sertão e da forma como a paisagem se apresenta. A partir do Itapicuru, diz o autor, o que surge é uma terra ignota. As massas humanas, ali, estancaram em vilarejos minúsculos, sem fixação e nem poderiam se fixar, pois a hostilidade do terreno é inclemente (Cunha, 1998, p. 20). Assim é que nos diz em: 
[e]stas lagoas mortas, segundo a bela etimologia indígena, demarcam obrigatória escala ao caminhante. (...) localizados em depressões, entre colinas nuas, envoltas pelos mandacarus despidos e tristes (...). Algumas denotam um esforço dos filhos do sertão. (...) Lembram monumentos de uma sociedade obscura. Patrimônio comum dos que por ali se agitam nas aperturas do clima feroz (...) (Cunha, 1998, p. 23, grifos nossos).

Assim como em:

As águas que fogem ao volver selvagem das torrentes, ou entre as camadas inclinadas dos xistos, ficam retidas, longo tempo, nas espatas das bromélias, aviventando-as. No pino dos verões, um pé de macambira é para o matuto sequioso um copo d'água cristalina e pura (Cunha, 1998, p.49, grifo nosso).

E em:

Se não existisse o umbuzeiro aquele trato de sertão, tão estéril que nele escasseiam os carnaubais tão providencialmente dispersos nos que os circunvizinham até o Ceará, estaria despovoado. O umbu é para o infeliz matuto que ali vive o mesmo que a mauritia, para os garaunos dos llanos (Cunha, 1998, p. 56, grifo nosso).

Não escapa ao olhar do autor a participação do homem no estado natural das paisagens em que “(...) assumiu, em todo o decorrer da História, o papel de um terrível fazedor de desertos" (Cunha, 1988, p. 62). Quanto ao sertão nordestino, Euclides informa que já os nativos tinham a prática de queimadas. O colonizador lhe seguiu o mesmo proceder e aliou-se a eles o sertanista ambicioso. As queimadas contribuíram para o clima demolidor que incide naquelas paragens, segundo o seu entendimento. Mas há soluções possíveis e parece estar convicto do poder criador do homem e de modo especial o homem do sertão, quando assim se refere ao resultado das queimadas "fez, talvez, o deserto. Mas pode extingui-lo ainda, corrigindo o passado. E a tarefa não é insuperável” (Cunha, 1998, p. 65). Em seguida, parte para indicar o que fazer com o solo a fim de que ele se beneficie dos períodos de inundação e não seja vitimado seguidamente por elas, quando propõe obras de engenharia que realize barramentos nos vales, de modo a reter as águas das chuvas.

\section{No texto "À margem da história"}

A obra de Euclides da Cunha é extremamente conhecida e lida, de modo que os recortes do texto apresentados nesta seção, não têm o condão de repetir os detalhes científicos 
ali fartamente descritos e aqui omitidos. Serão apresentados os pontos mais indicados para compor a lógica do que está se propondo: Euclides da Cunha lança mão da paisagem e se compromete em ser fiel à ciência do seu tempo em sua descrição, com uma intencionalidade que, no geral, é intervir positivamente na realidade dos eventos históricos do seu tempo em favor do sertanejo, sobrevalorizando a sua bravura.

Ao contrário de "Os Sertões", em que a paisagem é hostil ao homem pela aridez, pelo calor intenso durante o dia e de noites geladas, pela seca e pelas inundações temporárias, mas que se constitui de ambiente antigo, até mesmo fossilizado, a paisagem amazônica surge como a terra imatura, onde o homem é um intruso inoportuno. Tem-se por certo que o homem considerado intruso aqui é o homem colonizador, pois há omissão do elemento indígena na análise euclidiana. A região lhe aparece como num estágio de arrumação, cujos rios são elementos desagregadores e hostis. Sobre isso, ele diz:

[b]asta mostrar-se de relance que, ainda nos casos mais simples, há no Amazonas um flagrante desvio do processo ordinário da evolução das formas topográficas. Em toda a parte, a terra é um bloco onde se exercita a molduragem dos agentes externos entre os quais os grandes rios se erigem como principais fatores, no lhe remodelarem os acidentes naturais, suavizando-os. Compensando a degradação das vertentes com o alteamento dos vales, corroendo montanhas e edificando planuras, eles vão em geral entrelaçando as ações destrutivas e reconstrutoras, de modo que as paisagens, lento e lento transfiguradas, reflitam os efeitos de uma estuaria portentosa (...) ao passo que no Amazonas, o contrário. $\mathrm{O}$ que nele se destaca é a função destruidora, exclusiva. A enorme caudal está destruindo a terra (Cunha, 1999, p. 5, grifo nosso).

Essa ação destruidora do rio faz desaparecer lugares em uma só noite e refaz lugares numa única enchente. Aos olhos de Euclides, essa inconstância do rio se transmuda para os homens. Tal é o rio, tal é o homem, ele diz. Nota-se que, nesse ponto, Euclides ainda está preso ao determinismo geográfico:

[t]udo vacilante, efêmero, antinômico, na paragem estranha onde às próprias cidades são errantes, como os homens, perpetuamente a mudarem de sítio, deslocando-se à medida que o chão lhes foge roído das correntezas, ou tombando nas terras caídas das barreiras (...) (Cunha, 1999, p. 10).

A instabilidade notada na paisagem e nos homens é indicada também quando o autor dedica um capítulo para tratar do Rio Purus, que é um rio diferenciado dos demais por já haver alcançado nível maior de maturação geológica, restando pouco a se fazer para que o homem nele alcance prosperidade material. No entanto, Euclides denuncia os exploradores 
que singram aquelas águas, acusando-os de indignidade por nada fazerem para melhorar seu leito. Com isso, o Rio Purus, que poderia se tornar uma grande alavanca do desenvolvimento regional, não passa de um rio abandonado, não somente pelos que ali se encontram a explorar as riquezas da floresta, mas também pelo governo. Ele cobra mais atenção com a região, por meio de melhoramentos na navegabilidade, e alerta que "precisamos incorporá-lo ao nosso progresso, do qual ele será, ao cabo, um dos maiores fatores, porque é pelo seu leito desmedido em fora que se traça, nesses dias, uma das mais arrojadas linhas de nossa expansão histórica" (Cunha, 1999, p. 28).

A intencionalidade crítica de Euclides é evidente. Contudo, por trás da descrição negativa do homem que explora a Amazônia, e mesmo do nativo tido por ele como indolente, está também a sua preocupação com a questão da nacionalidade, quando irá propor como alternativa o "Sertanejo Forte" transmudado em "Caboclo Titânico", como sendo o indicado a promover a integração regional à nação, em face de não ser um intruso porque fixou-se na terra e venceu a sua hostilidade natural. É aqui que se percebe que a dureza e a hostilidade da natureza instável, estranhamente anfíbia e extraterrestre, como assim o autor se expressa, não fora descrita sem intenção determinada. Ela serve para indicar possibilidades de políticas de desenvolvimento regional, como também para encarecer o valor dos homens mais bemdotados para o desvendamento da raça brasileira. Cunha escreve:

[h]á alguma coisa extraterrestre naquela natureza anfíbia, misto de águas e de terras, que se oculta, completamente nivelada, na sua própria grandeza. (...) As gentes que a povoam talham-se-lhe pela braveza. Não a cultivam, aformoseando-a: domam-na. O cearense, o paraibano, os sertanejos nortistas, em geral, ali estacionam, cumprindo, sem o saberem, umas das maiores empresas destes tempos. Estão amansando o deserto (CUNHA, 1999, p. 29, grifos nossos).

É o caboclo titânico que dilatou a pátria e transmudou uma região despovoada em um estado - o Acre - e suas conquistas que se credencia como tipo humano capaz de consolidar a nação. A paisagem, portanto, se configura nas obras euclidianas para além da mera ambientação, como se fora uma moldura de arte poética que vem para escamotear uma definição científica ausente (Lima, 1997), principalmente quando se trata da paisagem amazônica. É, antes, o resultado de uma intencionalidade literária, cujo objetivo é descrever o ambiente hostil, tanto do Nordeste, quanto da Amazônia, de modo a valorizar a bravura de sua gente, para que o novo homem brasileiro seja identificado como aquele que vence o seu meio 
ambiente e não apenas se deixa dominar por ele ou que se amolde à cultura de empréstimo ${ }^{5}$. A descrição da paisagem é um elemento do vir-a-ser nacional, porque em sua hostilidade revelou o homem forte que poderá se constituir no homem brasileiro. $\mathrm{O}$ homem, suplantando o ambiente que lhe é hostil, adapta-se, forja-se e se habilita a constituir a raça nacional. Portanto, a paisagem adquire importância porque nela se revela a força do homem.

\section{Considerações finais}

Tem-se por certo, que o enfoque no tema paisagem nas duas obras analisadas se deve a duas razões principais. A primeira é resultante do momento histórico vivido pelo autor, inserindo-se num período da história da literatura, ou das ciências sociais, em que não havia distinção nítida entre Literatura e Ciência, de modo que o senso comum entre os autores era que o autor tinha por obrigação abarcar o máximo possível de aspectos da realidade. Trata-se de um senso comum douto. A segunda razão se deve a uma intencionalidade autoral que visa circunstanciar a hostilidade do ambiente natural, de modo a encarecer as lutas do homem. $\mathrm{O}$ autor pretendeu apresentar o sertanejo como um sujeito forte e a gravidade com que as agruras naturais são descritas, traduz uma estratégia do autor de valorizar as ações desse homem do sertão. O sertanejo é aquele que vence uma natureza bravia. Ele é o titã que amansa o deserto e que doma a terra, daí a sua dignidade.

Em outro ângulo, o tema paisagem também foi tratado como topofiliação, o amor pelo lugar. A proposta findou por se constituir numa defesa franca e ardente de Euclides da Cunha, tido como preconceituoso em relação à região amazônica. O desgosto e a insatisfação de Euclides da Cunha pela paisagem amazônica, dentre outros fatores, se deve ao padrão de belo incorporado em sua experiência topofílica, a qual é extremante diversa da paisagem amazônica, rica em referenciais paisagísticos permanentes, tais como montanhas e morros. Portanto, o seu estranhamento resulta de uma condição pessoal, da qual ele não poderia se livrar sem reflexão profunda. Euclides não manifestou o mesmo estranhamento em relação aos sertões baianos porque o relevo daquela região é muito próximo ao relevo de sua topofiliação, com os paredões de pedras, os vales, as serras, os morros, de modo que, ao revêlas, essas imagens evocaram nele os mesmos sentimentos de admiração e devoção que são os sentimentos que invadem o nativo frente ao seu lugar. Não há profundas divergências entre o relevo do sertão baiano com o relevo da região serrana do Rio de Janeiro, contrariamente à

${ }^{5}$ Note-se que Euclides omite o elemento indígena nesse processo. 
regularidade da paisagem amazônica e seu verde sempre constante, espalhada no plano, quase indistinta para os olhares estrangeiros.

Houvesse Euclides vivido mais tempo, teria a oportunidade de desfazer essa primeira má impressão e, quem sabe, no livro que nunca nasceu - "Um Paraíso Perdido" - afirmasse contrariamente o que disse em "À Margem da História”, já que seus últimos dias foram de intensa pesquisa sobre a região e, por diversas vezes, se referiu à Amazônia como "meu deserto". Nesse sentido, é possível conjecturar que Euclides da Cunha caminhava para uma conciliação com a paisagem amazônica, pois manifestou por diversas vezes o desejo de retornar à região. Por incrível que possa parecer, o isolamento da região, que foi o elemento que ele mais ressaltou como um problema para o homem sertanejo, foi para ele mesmo, o elemento que mais tocou a sua alma. Há elementos para se afirmar que em razão das experiências vividas na Amazônia, incluindo aí uma experiência de quase morte por alagamento do barco em que navegava e uma experiência de sucesso e reconhecimento como explorador e homem de Estado, Euclides se reconciliaria com a paisagem amazônica. Essas duas experiências são os elementos capazes de gravar na memória um sentimento fixador da paisagem enquanto lugar de vivência. Esse sentimento que vincula a imagem à experiência é o que permite que a paisagem se transforme em lugar. E o que é o lugar senão um constructo da mente num espaço determinado? O lugar, uma vez construído, é capaz de evocar sentimentos de pertencimento, de saudade, de orientação, entre outros.

É nesse sentido de pertencimento que se deve olhar a expressão "meu deserto" de Euclides da Cunha. Ela é um sinal de que já se processava nele, ao tempo dessa expressão, uma mudança de olhar em relação ao ambiente físico amazônico, em função de uma experiência profunda vivida na região, que agora alcança status de dignidade e evoca sentimentos positivos e de pertencimento. Afinal, a Amazônia venceu Euclides. O deserto seduziu o solitário. Em seu "testamento", a confissão: Amazônia, "meu deserto".

Euclides da Cunha apreendeu as singularidades e especificidades mais profundas do ethos amazônico em um curto espaço de tempo que por essa região percorreu, em uma única viagem ao Rio Purus. Nenhum outro autor antes dele havia enxergado a solidão do caboclo do beiradão como um elemento literário, como um traço da vida humana digno de ser perpetuado em um texto escrito. A percepção da necessidade de tornar a posse brasileira de vastas regiões do Norte em uma realidade tangível o coloca entre os pioneiros do assunto e é suficiente para "mantê-lo vivo", pois a cobiça internacional da região não arrefeceu, mas, pelo contrário, recrudesceu desde então. 
A genialidade e o ineditismo de Euclides residem no fato de que ele não se deixou translumbrar pela estonteante grandeza da região, mas tratou acerca das maneiras de torná-la viável para o homem que nela habita. Hodiernamente, os discursos de preservação da Amazônia estão difusos na sociedade brasileira e estrangeira, como o discurso "do corte e/ou do desmatamento zero na Amazônia", no qual artistas e intelectuais importantes da cena brasileira e estrangeira, muitas vezes de maneira acrítica, se posicionam a favor, sem, contudo, apontar alternativas para a manutenção da vida de mais de 20 milhões de almas que vivem em toda a Amazônia Legal. Por outro lado, as questões levantadas por Euclides quanto à Integração regional da Amazônia não se esgotaram nele mesmo, pois o legado do autor continua ativo, ainda que seja na qualidade de um legado precursor, posto que suas teses não apenas foram debatidas, mas levadas em conta por governos.

No entanto, é nele também que se encontra, de um modo desfavorável, o retrato da vida enquanto civilização. Euclides falou do caminho que leva a lugar nenhum, ou melhor, do caminho que leva sempre ao mesmo lugar. E, assim, contrariando o próprio objetivo de integrar a Amazônia ao restante do país, o seu diagnóstico, na verdade, transmudou-se em profecia de realidade futura, pois ele parece ter descoberto e falado da sina da região de viver em ciclos, ou em círculos. A mística da trilha do seringueiro parece ter-se impregnado na história social da Amazônia, pois, desde então, é assim que se vive, experimentando a gangorra de faustos-debacles-e-prorrogações, como Sísifo, condenado a um eterno recomeço. É a perpetuação da estrada de corte sobre os destinos locais.

Houvesse Euclides da Cunha esquecido o tema Integração regional e tivesse mantido apenas sua percepção poética da condição de isolamento desumanizante em que vivem muitas almas amazônicas, isso seria suficiente para tê-lo como um grande referencial. Somente quem já experimentou a solidão dos beiradões é que pode ter a noção exata do que nos falou Euclides. Ainda que o advento da tecnologia das antenas rurais tenha modificado em muito essa realidade, não está à disposição de todos. Para muitos ribeirinhos, um acidente com sangramento grave pode representar a sua morte, pois não há que se falar em socorro. Mesmo na zona urbana, em grande parte dos municípios amazônicos, o único caminho de socorro ainda é o rio, pois não há aeroportos e nem voos regulares, não há estradas, quase sempre há um único médico, ou nenhum. Ainda hoje, viver na Amazônia e sertão nordestino é mais difícil do que morrer. 


\section{Referências}

AMORY, Frederic. Euclides da Cunha: uma odisseia nos trópicos. Trad. Geraldo Gerson de Souza. Cotia, São Paulo: Ateliê Editorial, 2009.

BOURDIEU, Pierre. O Poder Simbólico. Lisboa: Difel, 1989.

CUNHA, Euclides da. À Margem da História. São Paulo: Martins Fontes, 1999 (Temas Brasileiros).

CUNHA, Euclides da. Os Sertões. Introdução Ricardo Oiticica. Rio de Janeiro: Record, 1998.

CUNHA, Euclides da. Peru versus Bolívia. São Paulo: Cultrix, 1975.

CUNHA, Euclides da. Poesia Reunida. Organização, estabelecimento de textos, introduções, notas e índices: Leopoldo M. Bernucci, Francisco Foot Hardman. São Paulo: Editora UNESP, 2009.

CUNHA, Euclides da. Um Paraíso Perdido: Reunião de Ensaios Amazônicos. Seleção e Coord. Hildon Rocha. Brasília: Senado Federal, 2000.

CUNHA, Euclides da. Amazônia: Um Paraíso Perdido. Organização: Tenório Telles. 2.ed. Manaus: Editora Valer, 2011.

LIMA, Luiz Costa. Terra Ignota: a construção de Os Sertões. Rio de Janeiro: Civilização Brasileira, 1997.

REFEITURA Municipal de Cantagalo. Disponível em: http://www.cantagalo.rj.gov.br/aspectos-geograficos/. Acesso em: março de 2016. Prefeitura Municipal de Cantagalo. Disponível em: http://www.cantagalo.rj.gov.br/aspectosgeograficos/. Acesso em: março de 2016.

SIMMEL, Georg. Filosofia da Paisagem. Trad. Artur Mourão. Covilhã: LosoSofia.press, 2009.

SCHNEIDER, Robert et al. Amazônia Sustentável: limitantes e oportunidades para o desenvolvimento rural. Brasília: Banco Mundial, 2000.

TUAN, Yi-Fu. Topofilia. Um estudo da percepção, atitudes e valores do meio ambiente. Tradução Lívia de Oliveira. Londrina: Eduel, 2012.

TUAN, Yi-Fu. Espaço e Lugar: a perspectiva da experiência. Tradução Lívia de Oliveira. Londrina: Eduel, 2013.

VAREJISTAS de Manaus temem ficar sem alimentos por conta de protestos: paralisação de caminhoneiros nas estradas ameaça abastecimento de produtos para o estado. Disponível em: 
Revista de Geografia (Recife) V. 34, No. 3, 2017

http://new.d24am.com/noticias/economia/varejistas-manaus-tememficar-alimentos/129583.

Acesso em: 22 dez. 2015. 